IJCCSM

9,6

864

\title{
Publisher's note
}

The Journal would like to bring to the attention of its readers that the article, "Nature and extent of population displacement due to climate change-triggered disasters in the southwestern coastal region of Bangladesh", has been published in identical form in both the International Journal of Climate Change Strategies and Management (Vol. 4 No. 1, pp. 54-65), doi: http://dx.doi.org/10.1108/17568691211200218, and Management of Environmental Quality: An International Journal (Vol. 22 No. 5, pp. 620-631), doi: http://dx.doi.org/10.1108/ 14777831111159743.

This was due to an editorial error and the publisher sincerely apologises for this. The publisher believes in this case a retraction would be unfair to the authors and instead both versions of the article will remain available online but with this Publisher's note attached to each. The publisher encourages readers to use the IJCCSM version of the article. The version published in $M E Q$ has been watermarked as a "duplicate".

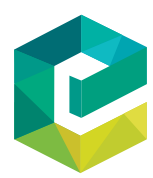

International Journal of Climate Change Strategies and

Management

Vol. 9 No. 6, 2017 p. 864

(c) Emerald Publishing Limited

$1756-8692$

DOI 10.1108/IJCCSM-11-2017-176 